\title{
SCIDiC
}

\author{
International Journal of Dentistry and Oral Science (IJDOS) \\ ISSN: 2377-8075
}

\section{Vernonia Amygdalina Mediated Copper Nanoparticles and its Characterization and Antimicrobial Activity - An In Vitro Study}

Research Article

S.Sushanthi ${ }^{1 *}$, Srisakthi Doraikannan ${ }^{2}$, MeignanaArumugham Indiran ${ }^{3}$, Pradeepkumar Rathinavelu ${ }^{4}$, Rajeshkumar $\mathrm{S}^{5}$

${ }^{1}$ Department of Oral and Maxillofacial Surgery, Saveetha Dental College, SIMATS, Saveetha University, Chennai 77, India.

${ }^{2}$ Professor, Department of Oral and Maxillofacial Surgery, Saveetha Dental College, SIMATS, Saveetha University, Chennai 77, India.

${ }^{3}$ Department of Oral and Maxillofacial Surgery, Saveetha Dental College, SIMATS, Saveetha University, Chennai 77, India.

\section{Abstract}

Background: The green approachable metal nanoparticles is treated to be an eco-friendly path and cost-effectiveness. In this present study, nano copper was synthesized profitably by Vernonia amygdalina. Vernonia amygdalina is generally known as sour leaf or bitter leaf which is one among the medically significant plants in African and Mediterranean regions.

Methods: Green synthesis of copper nanoparticles was preliminarily confirmed by color changefrom blue to brown in the reaction mixture. The synthesized nanoparticles were characterized by using ultraviolet double beam spectrophotometer in the wavelength range of $250-750 \mathrm{~nm}$. The oral pathogenssuch as Streptococcus mutans, Staphylococcus aureus and Enterococcus faecalis and C. albicans were used to assess the antimicrobial efficacy ofV. amygdalinareinforced Copper nanoparticles. Antimicrobial activity was done according to the Agar well diffusion method atvarious concentrations that ranges from $25 \mu \mathrm{L}, 50 \mu \mathrm{L}$ and $100 \mu \mathrm{L}$. Results: Zone of inhibition was found to be highest at $100 \mu \mathrm{L}$ against Streptococcus mutans, Staphylococcus aureus, Enterococcus faecalis and Candida albicans. The mean zone of inhibition was found to be increased as the concentrations of $\mathrm{Cu} N \mathrm{Ns}$ increased.

Conclusion: Green synthesis of copper nanoparticles was initially confirmed by the position of SPR band at $340 \mathrm{~nm}$ in UV-Vis spectra. From the findings of the study, we can conclude that V. amygdalinareinforced copper nanoparticles have good antimicrobial efficacy against oral microorganisms.

Keywords: Copper Nanoparticles, Green Synthesis, Vernonia Amygdalina, Antimicrobial.

\section{Introduction}

Herbal medicines which are otherwise known as phytomedicines, medicinal products of plants or plant parts such as roots, leaves, flowers, barks, seeds and fruits which is widely used to treat various diseases and also to improve the health condition. Herbal medicines which are also called complementary medicines, have been used to ease the pain and to mitigate the diseases and their symptoms [1]. Many plants and fruits which are recognized with abundant sources of phenolic compounds which have many useful properties including antioxidant, antibacterial, anti-inflammatory, hepatoprotective and anticarcinogenic actions [2-4].

Vernonia amygdalina is a soft woody shrub or tree belonging to the family Asteraceae and genus Vernonia [5]. It is a perennial plant character- ized by its bitter sap from the leaf which has been widely known for its medicinal use. V. amygdalina is commonly used as an antidiabetic [6], antihelminthic [7] and antimalarial medicinal plant [8] and also used to treat digestive disorders. +e main bioactive constituents of the leaves were reported as sesquiterpene lactones [9] and also vernonioside A1, vernonioside A2, vernonioside B1, vernonioside B2 $[12,13]$, vernodalin, vernolepin, vernomygdin, vernodalol, and vernodalin [10]. Furthermore, V. amygdalina has also been used traditionally to treat toothache which is not studied in detail.

Nanotechnology includes the production, manipulation and use of materials ranging in size from less than a micron to that of individual atoms [11]. Using plants for nanoparticles synthesis can also be advantageous over other biological processes because of

*Corresponding Author:

S.Sushanthi,

Department of Oral and Maxillofacial Surgery, Saveetha Dental College, SIMATS, Saveetha University, Chennai 77, India.

Tel: 6383746057

E-mail: sushaantheesuresh@gmail.com

Received: May 04, 2021

Accepted: July 09, 2021

Published: July 19, 2021

Citation: S.Sushanthi, Srisakthi Doraikannan, Meignana Arumugham Indiran, Pradeepkumar Rathinavelu, Rajeshkumar S. Vernonia Amygdalina Mediated Copper Nanoparticles and its Characterization and Antimicrobial Activity - An In vitro Study. Int J Dentistry Oral Sci. 2021;8(7):3330-3334. doi: http://dx.doi.org/10.19070/2377-8075-21000678

Copyright: S.Sushanthi 2021 . This is an open-access article distributed under the terms of the Creative Commons Attribution License, which permits unrestricted use, distribution and reproduction in any medium, provided the original author and source are credited. 
huge availability of plants materials and also it eradicate the ease of large scale up and the process of culture maintaining, and in turn no use high pressure, energy, temperature and toxic chemical [12]. Plant extracts which have the unique property to act as reducing and capping agent which used in the reduction of metal ions, used in many pharmaceutical preparations [13]. The chapter in nanotechnology which currently provokes the interest of researchers is the noble metal nanoparticles which have the good antibacterial property due to their large surface area to volume ratio [14]. Obviously among the metallic nanoparticles, copper has been probably utilized most due to its stable and catalytic properties. Copper nanoparticles have wide applications as heat transfer systems and also as antimicrobial materials $[15,16]$. V. amygdalinamediated silver nanoparticles [17] and zinc oxide nanoparticles $[18,19]$ was recently reported that it shows good microbial properties against bacteria.

In this study we are using leaf extract of Vernonia amygdalina plants for synthesis of copper nanoparticles at room temperature. Copper nanoparticles synthesis was identified by colour change and UV- visible spectroscopy (UV-vis) and it is confirmed by Transmission electron microscopy. Furthermore, the bacterial effect of Copper nanoparticles was also analyzed with gram positive and gram-negative microorganisms. The main aim of the present study was to synthesize Copper nanoparticles using the leaf extract of Vernonia amygdalina and to evaluate their antimicrobial efficacy against some selected oral microbes.

\section{Materials And Methods}

\section{Preparation of aqueous leaf extract}

Vernonia amygdalina was bought from Nigerian market. The collected leavesof V. amygdalina were washed 3-4 times using distilled water and shade dried for 7-14 days. The well dried leaves were grinded into fine powder (Figure 1a). The collected powder was stored in an air-tight container. About $1 \mathrm{~g}$ of $\mathrm{V}$. amygdalina powder was measured and dissolved in $100 \mathrm{~mL}$ distilled water and boiled for $5-10$ minutes at $60-70^{\circ} \mathrm{C}$. The solution was filtered by using Whatman no. 1 filter paper. The filtered extract was collected and stored in $4^{\circ} \mathrm{C}$ for further use (Figure $1 \mathrm{~b}$ ).

\section{Synthesis of NPs}

The copper nanoparticles were synthesized by adding $20 \mathrm{mM}$ of copper sulphate(Figure $2 \mathrm{a}$ ) to $80 \mathrm{ml}$ of distilled water. To that $20 \mathrm{ml}$ of filtered V.amygdalina leaf extract was added and kept under constant stirring using a magnetic stirrer at $45-50{ }^{\circ} \mathrm{C}$ for $72 \mathrm{~h}$. The colour change gradually changed from light blue to dark green colour (Figure 2c). At the end, the centrifugation process was carried out to separate synthesized copper nanoparticles from supernatant solution. The obtained pellet after was washed twice with deionized water and dried in a hot air oven at $100^{\circ} \mathrm{C}$ for $3 \mathrm{~h}$. Finally, the dried powder was stored in properly labeled Eppendorff tube and used for further analysis.

\section{Characterization of copper nanoparticles}

The biosynthesis of CuNPs werepreliminary characterized using UV-visible spectrophotometerat 300 to $700 \mathrm{~nm}$ wavelength. The results were recorded for the graphical analysis. The aqueous copper nanoparticles and the optical properties were characterized by UV-spectrophotometer (Elico, India). The shape and size of the copper nanoparticles were analysed by using Transmission Electron Microscope (JEOL JEM3100F). The crystalline nature of the nanoparticles were characterized by X-ray diffraction analysis and the Fourier transform infrared spectroscopy was used to detect the functional and chemical group in the range of 4000-400 $\mathrm{cm}$.

\section{Antimicrobial activity of Vernonia amygdalina mediated CuNPs}

Thecopper nanoparticles reinforced with Vernonia amygdalinaleaf extract were tested for antimicrobial efficiency by agar well diffusion method. The antibacterial activity of copper nanoparticles wastested against four different oral pathogens like Enterococcus faecalis, Staphylococcus aureus, Streptococcus mutans and the antifungal activity was tested against C. albicans. Different concentrations of NPs $(25,50$, and $100 \mu \mathrm{L})$ were incorporated into the wells and the plates were incubated at $37^{\circ} \mathrm{C}$ for $24 \mathrm{~h}$. The antibiotic amoxyrite was used as standard and for C. albicans

Figure 1. (a) Powdered form of V. amygdalina (b) Aqueous extract of Vernonia amygdalina.

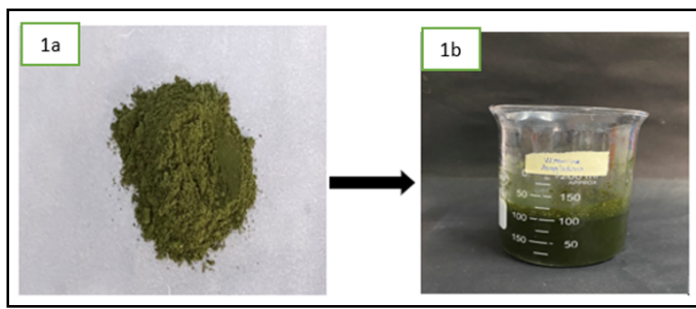

Figure 2. (a) Copper sulphate solution (b) Vernonia amygdalina mediated CuSo4 (c) After 72 hours.

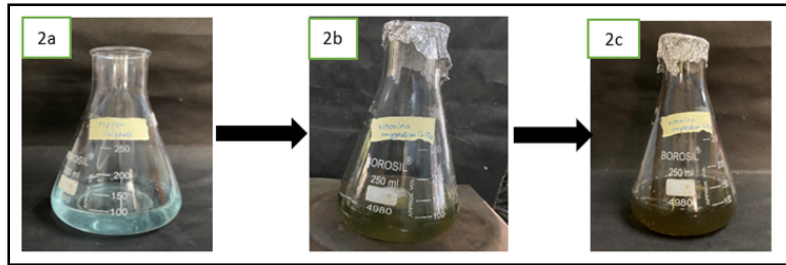


fluconazole was used as standard control. Zone of inhibition was measured for each plate after 24 hours. The experiments were conducted based on our previous studies.

\section{Results}

Nanosized materials are having a great interest due to their unique optical properties. Nanoparticles exhibit different arrays of colours during the synthesis process. Plant extract contains several phytochemicals that react with copper sulphate and converts into copper nanoparticles and it was primarily identified by the change of colour from blue to brown in the reaction mixture observed within $1 \mathrm{~h}$ (Figure $3 \mathrm{a}$ ). After $24 \mathrm{~h}$ reaction, the colour changing reaction was stopped and precipitation was observed which indicates that the nanoparticle synthesis process was completedAshtaputrey et al. [21]

\section{UV- Visible Spectroscopy}

UV-Vis absorption spectra of the green synthesized copper nanoparticles were recorded at a different wavelength from 250$750 \mathrm{~nm}$ shown in Figure 3b. The copper nanoparticles are synthesized using copper sulphate and Vernonia amygdalina leaf extract as a reducing agent which shows absorption peak at 340 $\mathrm{nm}$. Broadened SPR peak observed in this UV-Vis spectrum confirmed that polydisperse nanosized particles. The peak found in the spectroscopy indicates the formation of V. amygdalina Cu NP.

\section{Transmission electron microscopy}

TEM is the most common tool to convict the structure, size, morphology, dispersion, and orientation of biological and physi-

Figure 3 a: Visual Observation of Vernonia amygdalina mediated CuSO4; 3b: UV-Vis spectroscopic analysis of nano copper Vernonia amygdalina mediated CuSO4.
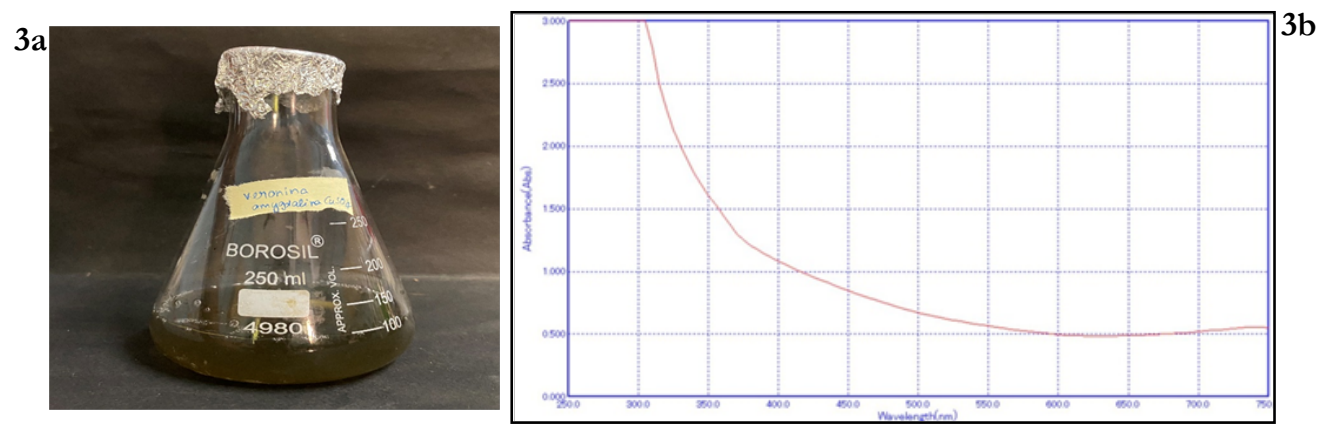

Figure 4: TEM image ofVernoniaamygdalina mediated Copper Nanoparticles.

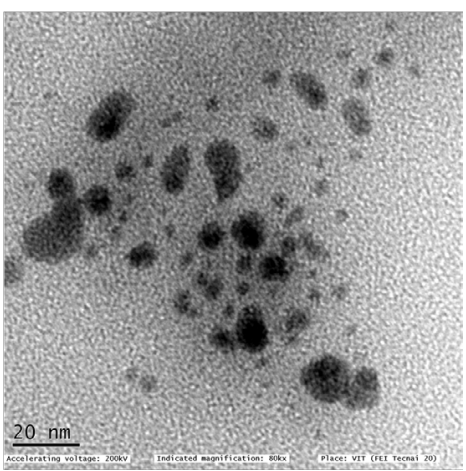

Figure 5: Antimicrobial activity of Vernonia amygdalina mediated Copper nanoparticles against pathogenic microorganisms (5a)Streptococcusmutans (5b)Streptococcus aureus (5c) E.Faecalis (5d) Candida albicans.
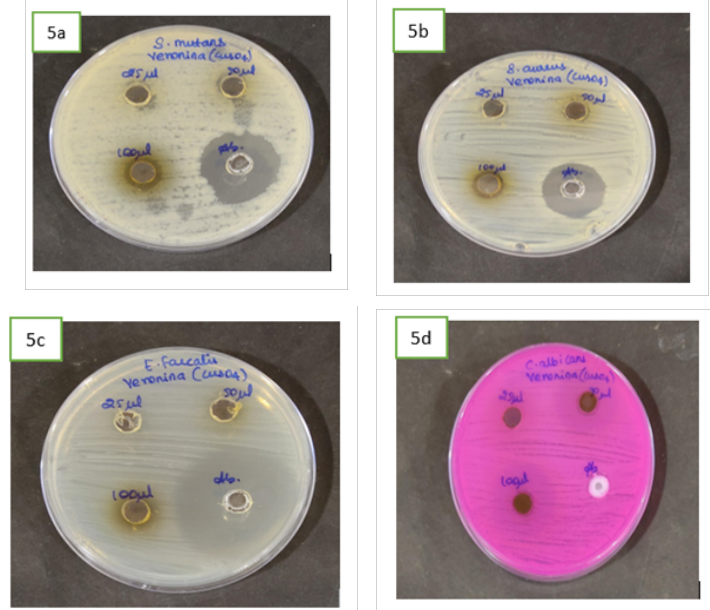
Figure 6: Antibacterial activity of Vernonia amygdalina mediated Nanoparticles.

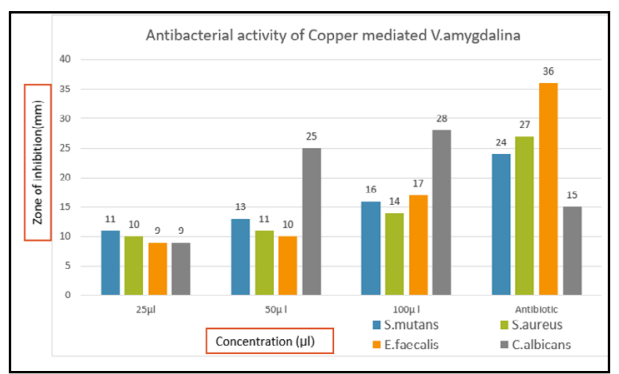

From the above graph in S. aureus, S.mutans, C.albicans, E.faecalis, the zone of inhibition increases with increase in concentration.

cal samples. Figure shows the typical TEM images of nano copper shape was found to be well dispersed, crystalline in nature andthe figure also confirms that shape of copper nanoparticles is spherical in shape and has the broad size distribution between6 to $20 \mathrm{~nm}$. This image explains that the copper nanoparticles arebounded with the phytochemicals of the plant extract.

\section{Antimicrobial Activity}

Agar well diffusion methodwas used to determine the antimicrobial activity of Vernonia amygdalina incorporated Copper nanoparticles against S.mutans, S.aureus, C.albicans, E.faecalis (Figure 5). The mean zone of inhibition was found to be increased as the concentrations of $\mathrm{Cu}$ NPs increased, producing a maximum zone of inhibition for S.mutans, and E.faecalis at $100 \mu$ l concentration.

\section{Discussion}

Several investigators had reported that plants contain antibacterial or antimicrobial substances $[21,22]$. Vernonia amygdalina used in the preparation of food nutritive seasoning and also in the preparation of food. Apart from its nutritive value, it has been found to be potential in inhibiting the growth of microorganisms. Several research works have reviewed the nutritive, chemical and proximate analysis of $V$. amygdalina [18]. Researchers have also studied the phytochemical and antimicrobial properties of leaf and stem extract. Phytochemicals present in Vernonia amygdalina included flavonoids, cardiac glycosides, reducing sugar, terpenoids, saponins, anthraquinones, and alkaloids [23].

The antibacterial activity of $V$ amygdalina was found to be dependent on the nature of the solvent used for extraction and the concentration of the extract. Ethanolic extract was observed to possess more antibacterial activities compared to the aqueous extract $[24,25]$.

Agar well diffusion methods were used to determine the antibacterial activity of different concentrations of Vernonia amygdalina incorporated CuS NPs against S.mutans, S.aureus, C.albicans, E.faecalis. Antimicrobial efficacy of E.faecalis was shown in the figure. The mean zone of inhibition was found to be increased as the concentrations of CuS NPs, produced a maximum zone of inhibition for S.mutans, E.faecalis, however maximum was found for ampicillin/fluconazole. At $100 \mu$ l concentration, maximum zone was produced for CuS NPs mediated V. amygdalina compared with fluconazole. Similar results were obtained by the study conducted by : I. I. Anibijuwon et al [26]. UV-Vis absorption spectra of the green synthesized copper nanoparticles were recorded at a different wavelength from 200-600 nm. The copper nanoparticles are synthesized using copper sulphate usingVernonia amygdalina leaf extract as a reducing agent displays an absorption peak at 340 $\mathrm{nm}$. This peak can be assigned to be synthesized copper nanoparticles using plant extract [27]. Antimicrobial activity of copper nanoparticles by green synthesis using V. amygdalina showed promising results [26].

\section{Recommendations}

- This product can be given to the patients in the form of a mouthwash.

- In further studies, in vivo studies are recommended with people' acceptance values as well.

\section{Conclusion}

This investigation concluded that Vernonia amygdalina extract based green synthesized copper nanoparticles can be used as an alternative to commercially available antimicrobial agents. Green synthesis of copper nanoparticles was initially confirmed by the position of SPR band at $340 \mathrm{~nm}$ in UV-Vis spectral.

Ethical Statement: Ethical approval was obtained from Institutional Human Ethical Committee, Saveetha Dental College.

\section{References}

[1]. Calixto JB, Santos AR, Filho VC, Yunes RA. A review of the plants of the genus Phyllanthus: their chemistry, pharmacology, and therapeutic potential. Med. Res. Rev. 1998 Jul;18(4):225-58.

[2]. Seeff LB, Lindsay KL, Bacon BR, Kresina TF, Hoofnagle JH. Complementary and alternative medicine in chronic liver disease. Hepatology. 2001 Sep;34(3):595-603.

[3]. Winslow LC, Kroll DJ. Herbs as medicines. Arch. Intern. Med. 1998 Nov 9;158(20):2192-9.

[4]. Khogta S, Patel J, Barve K, Londhe V. Herbal nano-formulations for topical delivery. J. Herb. Med. 2020 Apr 1;20:100300.

[5]. Phytochemical and Antibacterial Activities of Vernonia Amygdalina Leaves (Bitter Leaf) on two Drug Resistant Bacteria . IJRSMB. 2020;6.

[6]. Eteng MU, Bassey BJ, Atangwho IJ, Egbung GE, Eyong EU, Ebong PE, et al. Biochemical indices of macrovascular complication in diabetic rat model: compared effects of Vernonia amygdalina, Catharantus roseus and chlorpropamide. Asian J Biochem. 2008;3:228-34.

[7]. Hasibuan PA, Harahap U, Sitorus P, Satria D. Evaluation of Antioxidant and Cytotoxic Activities of Vernonia amygdalina Del. Leaves. Proceedings of BROMO Conference. 2018.

[8]. Magadula JJ, Erasto P. Bioactive natural products derived from the East African flora. Nat Prod Rep. 2009 Dec;26(12):1535-54.Pubmed PMID: 19936385.

[9]. Sobrinho AC, de Souza EB, dos Santos Fontenelle RO. A review on antimicrobial potential of species of the genus Vernonia (Asteraceae). J. Med. Plant Res. 2015 Aug 17;9(31):838-50.

[10]. Igile G, Olenszek W, Jurzysta M, Aquino R, de Tommasi N, Pizza C. Vemoniosides $\mathrm{D}$ and $\mathrm{E}$, two novel saponins from Vernonia amygdalina. J. Nat. 
Prod. 1995 Sep;58(9):1438-43.

[11]. Rajeshkumar S, Kumar SV, Ramaiah A, Agarwal H, Lakshmi T, Roopan SM. Biosynthesis of zinc oxide nanoparticles usingMangifera indica leaves and evaluation of their antioxidant and cytotoxic properties in lung cancer (A549) cells. Enzyme Microb Technol. 2018 Oct;117:91-95.Pubmed PMID: 30037558.

[12]. Paulkumar K, Gnanajobitha G, Vanaja M, Rajeshkumar S, Malarkodi C, Pandian K, et al. Piper nigrum leaf and stem assisted green synthesis of silver nanoparticles and evaluation of its antibacterial activity against agricultural plant pathogens. ScientificWorldJournal. 2014 Jan 15;2014:1-9.Pubmed PMID: 24558336.

[13]. Varadharajan V, Ramaswamy A, Shanmugham S. Silver Nanoparticle Synthesis Using Grape (Vitis vinifera L.) Skin Extract and Its Application as Anticancerous Agent. Adv. Sci. Eng. Med. 2016 Aug 1;8(8):626-34.

[14]. Yang Y. The study and exploration about nanotoxicity of oxide nanoparticles on escherichia coli and exiguobacterium sibiricum. Michigan State University. Department of Crop and Soil Science; 2009:340.

[15]. Guduru RK, Murty KL, Youssef KM, Scattergood RO, Koch CC. Mechanical behavior of nanocrystalline copper. Mater. Sci. Eng: A. 2007 Aug $15 ; 463(1-2): 14-21$

[16]. Rajeshkumar S, Rinitha G. Nanostructural characterization of antimicrobial and antioxidant copper nanoparticles synthesized using novel Persea americana seeds. OpenNano. 2018 Jan 1;3:18-27.

[17]. Aisida SO, Ugwu K, Akpa PA, Nwanya AC, Nwankwo U, Botha SS, et al. Biosynthesis of silver nanoparticles using bitter leave (Veronica amygdalina) for antibacterial activities. Surf. Interfaces. 2019 Dec 1;17:100359.

[18]. Liu H, Kang P, Liu Y, An Y, Hu Y, Jin X, et al. Zinc oxide nanoparticles synthesised from the Vernonia amygdalina shows the anti-inflammatory and antinociceptive activities in the mice model. Artif Cells Nanomed Biotechnol. 2020 Dec;48(1):1068-1078.Pubmed PMID: 32815404.
[19]. Mfon R. Characterisation of silver and zinc oxide nanoparticles biosynthesized using Ocimum gratissimum and Vernonia amygdalina plant leaf extracts (Doctoral dissertation, University of Bristol). 2019.

[20]. Ashtaputrey SD, Ashtaputrey PD, Rathod GU. Eco-friendly green synthesis and characterization of silver nanoparticles derived from Murraya koenigii leaves extract. Asian J. Chem. 2017;29(9):1966-8.

[21]. Rajeshkumar S. Synthesis of silver nanoparticles using fresh bark of Pongamia pinnata and characterization of its antibacterial activity against gram positive and gram negative pathogens. Resource-Efficient Technologies. 2016 Mar 1;2(1):30-5.

[22]. Vanaja M, Gnana Jobitha G, Paul Kumar K, Rajeshkumar S, Malarkodi C, Annadurai G. The Synthesis of silver nanoparticles by Cissus quadrangularis: influence of physicochemical factors. J Nanostructure Chem. $2013 \mathrm{Apr}$ 22;3(1):17.

[23]. Alara OR, Abdurahman NH, Ukaegbu CI, Kabbashi NA. Extraction and characterization of bioactive compounds in Vernonia amygdalina leaf ethanolic extract comparing Soxhlet and microwave-assisted extraction techniques. J. Taibah Univ. Sci. 2019 Dec 11;13(1):414-22.

[24]. Evbuomwan L, Chukwuka EP, Obazenu EI, Ilevbare L. Antibacterial activity of Vernonia amygdalina leaf extracts against multidrug resistant bacterial isolates. J Appl Sci Environ Manage. 2018 Feb 7;22(1):17-21.

[25]. Lasserre B, Kaiser R, Chanh PH, Ifansyah N, Gleye J, Moulis C. Effects on rats of aqueous extracts of plants used in folk medicine as antihypertensive agents. Naturwissenschaften. 1983 Feb;70(2):95-6.

[26]. ANIBIJUWON I, OLADEJO B, ADETITUN D, KOLAWOLE O. Antimicrobial activities of Vernonia amygdalina against oral microbes.2012.

[27]. Wu S, Rajeshkumar S, Madasamy M, Mahendran V. Green synthesis of copper nanoparticles using Cissus vitiginea and its antioxidant and antibacterial activity against urinary tract infection pathogens. Artif Cells Nanomed Biotechnol. 2020 Dec;48(1):1153-1158.Pubmed PMID: 32924614. 